REVIEW

\title{
Human cellular inflammation in the pathology of acute cerebral ischaemia
}

\author{
C J S Price, E A Warburton, D K Menon
}

Leucocytes form important effector pathways for inflammation. This article reviews the clinical evidence for the presence of a cellular inflammatory response in cerebral ischaemia, and attempts to define its temporal profile and spatial distribution. The processes involved in recruitment and activation of leucocytes in this context are addressed, and the successes and failures of interventions aimed at these processes discussed.

See end of article for authors' affiliations

.....................

Correspondence to:

Dr Christopher J S Price,

Box 83 (R3 Neuroscience), Addenbrooke's Hospital,

Cambridge CB22QQ, UK; cp252@

medschl.cam.ac.uk

Received

19 December 2002

In revised form

23 May 2003

Accepted 9 June 2003
$\mathrm{T}$ he pathophysiological consequences of acute ischaemic stroke are still not fully understood. There is much evidence, largely derived from animal models, to suggest that neuroinflammatory mechanisms play an important role in ischaemic injury, and that interruption of these processes can result in improved neurological outcomes. These animal data have been comprehensively examined in a series of recent review articles on the topic (table 1 ), and the evidence they provide has been persuasive enough for large scale clinical trials of antiinflammatory agents to be undertaken. $^{12}$ However, two large recent trials of treatment aimed at neutrophil adhesion have been unsuccessful, despite the recruitment of large numbers of patients. These failures of anti-inflammatory therapy form part of a larger picture, where experimental success with neuroprotection has not been translated into the clinical arena. The causes for this failure have been reviewed by expert bodies, ${ }^{3}$ and their conclusions are in general applicable to the field of anti-inflammatory treatment in stroke. While a detailed discussion of the experimental data supporting a pathogenic role of inflammation in acute stroke is covered by the reviews cited in table 1 , it is useful to list some of the confounding variables that may have contributed to the differences between animal and clinical studies (table 2 ).

It is also relevant that animal models of stroke are extremely heterogeneous. For example, models of permanent middle cerebral artery occlusion do not have reperfusion, while those of transient middle cerebral artery occlusion do. Not only will the extent of reperfusion modify the amount of penumbral tissue available for neuroprotection, but the absence of reperfusion will limit the access of inflammatory processes to the ischaemic brain and may thus attenuate the efficacy of anti-inflammatory interventions. Further, data on the spatial localisation of inflammatory activation are sparse. As inflammation in the core infarct area may be of limited relevance as a
J Neurol Neurosurg Psychiatry 2003;74:1476-1484

therapeutic target, spatial localisation of these processes is critical.

Such considerations also apply to the assessment of clinical trials, where no distinction is usually made regarding the presence or absence of reperfusion, and there is little or no information about the spatial localisation of inflammatory processes in the brain. There remains a need to describe the clinical pathophysiology of stroke more appropriately, and to identify how such information can be translated into clinical trials. In this review we will focus on the clinical pathophysiology of human stroke in the context of the inflammatory response.

\section{THERAPEUTIC TARGETS IN STROKE: THE ROLE OF CELLULAR INFLAMMATION}

The entire spectrum of inflammatory processes is likely to act in concert in stroke. The principal constituents of this process have been extensively reviewed in recent articles, primarily in the context of experimental stroke (table 1). While collated data on clinical stroke are more difficult to access, the relevant results have usually been reviewed in the context of animal data in the papers cited. Relatively little attention has been paid to the process of vascular leucocyte recruitment and activation in clinical stroke. These processes are crucial end products of the inflammatory response, and may often be the proximate cause of tissue injury. Importantly, the inhibition of leucocyte trafficking into the CNS may present an accessible therapeutic target, not least because the processes involved remain outside the blood-brain barrier and should be modifiable. Several important issues require attention in this setting.

The first is whether inflammation is restricted to the ischaemic core of the lesion (where it is unlikely to be a therapeutic target) or whether it

Abbreviations: CINC, cyłokine induced neutrophil chemoattractant; ELISA, enzyme linked immunosorbent assay; HMPAO, hexamethylpropylene amine oxime; ICAM, intercellular adhesion molecule; IL, interleukin; MCP, monocyte chemoattractant protein; MIP, macrophage inflammatory protein; MMP, matrix metalloproteinase; NAP, neutrophil activating protein PBBS, peripheral-type benzodiazepine binding site; PET, positron emission tomography; PSGL, P-selectin glycoproteins ligand; RANTES, regulated on activation normal T cell expressed and secreted; RNA, ribonucleic acid; SDF, stromal cell derived factor; SLC, secondary lymphoid tissue chemokine; SPECT, single photon emission tomography; TIA, transient ischaemic attack; TNF, tumour necrosis factor; VCAM, vascular cell adhesion molecule 
Table 1 Recent reviews of inflammatory processes in stroke

\begin{tabular}{ll}
\hline Subject & References \\
\hline Overviews & $4-10$ \\
Interleukin-1 & 1112 \\
Tumour necrosis factor $\alpha$ & 1314 \\
Adhesion molecules & 1516 \\
Nitric oxide & 48 \\
Infection & 10 \\
\hline
\end{tabular}

is prominent in the penumbra, where it may contribute to infarct expansion. Second, it is important to identify the cell populations that are responsible for inflammation after stroke, and map their recruitment to the CNS in the context of structural images using magnetic resonance imaging (MRI) or computed tomography (CT). Leucocyte recruitment and activation may contribute to tissue injury following stroke, but the proof of this proposition depends on the attenuation of tissue injury by anti-inflammatory interventions. The success of such studies will be critically influenced by choice of targets, and the timing and nature of interventions used will vary, depending on whether the processes targeted are early or late, transient or persistent, or chiefly comprised of blood derived leucocytes or intrinsic CNS microglia. Clinical trials aimed at attenuating proinflammatory processes are largely based upon extrapolation of animal data where such data do not exist within the clinical arena. Hence the mechanisms responsible for leucocyte recruitment need to be understood, as they may well represent accessible targets for treatment.

In this paper we will focus on the evidence for human vascular leucocyte recruitment following cerebral ischaemia, and attempt to dissect its mechanism, temporal profile, and spatial distribution. We will also address key mediators responsible for leucocyte recruitment, including chemokines and adhesion molecules. Despite limited evidence for a direct inflammatory role for $\mathrm{C}$ reactive protein-in addition to its place as marker of disease severity-this remains nonspecific to the cellular response and we have not included it in the article. Furthermore, we have not attempted to cover experimental studies but have included clinical interventional studies aimed at the processes that we describe.

\section{LEUCOCYTES}

Leucocytes represent one of the most important effector mechanisms of the inflammatory process, and there is increasing experimental evidence that they accumulate in the brain following cerebral ischaemia. However, within the clinical context such studies are limited with respect to the subtype of leucocyte involved, their mechanistic involvement, the spatial and temporal pattern of their recruitment, and allowance for confounding factors such as sepsis, glycaemic status, temperature, and infarct volume.

\section{Cellular inflammatory response in clinical stroke}

In contrast to data relating to experimental ischaemia, direct histological evidence of leucocyte recruitment in human stroke is limited to a few small necropsy studies. While these reports support leucocyte involvement in the disease process, they cannot provide information on the temporal profile of leucocyte recruitment, and in particular, they supply no information on the role of these cells in early stroke, where they may represent a useful therapeutic target. Thus clinical studies have mainly focused on changes in peripheral leucocytes in clinical cerebral ischaemia. More recent studies, however, have used modern imaging techniques to delineate the biology of cellular inflammatory responses following stroke.

\section{Peripheral leucocytes in patients with ischaemic stroke and at risk of stroke}

Epidemiological studies have suggested that a raised peripheral neutrophil count may predict increased stroke incidence through a presumed prothrombotic mechanism. ${ }^{18} 19$ Such predictions and presumptions offer at best circumstantial evidence for a role in aetiology, and few insights into mechanisms. Enhanced peripheral leucocyte activation and levels of complement factor 3 (C3) have been documented in acute stroke, with contrasting correlations with infarct volume (measured radiologically) and total leucocyte counts. $^{2021}$ Such studies may be consistent with CNS leucocyte sequestration from peripheral populations, and prompt the suggestion that subpopulations of these cells may be responsible for the inflammatory response. Whether leucocytes are activated primarily in the periphery or in the CNS before sequestration remains to be established. Additional work in this area-examining leucocyte/platelet adhesiveness, leucocyte influence on plasma, and pseudopod formation-does not contribute direct evidence for neuroinflammation in the aetiology of stroke. ${ }^{22-26}$

\section{Changes in cerebral infarction \\ CSF cytology and histology}

Cerebrospinal fluid analysis from patients with ischaemic stroke shows the presence of both polymorphonuclear leucocytes (neutrophils) and monocytes/macrophages. An early neutrophil reaction in the CSF has been documented in clinical ischaemic stroke (less than that seen in primary cerebral haemorrhage), while monocytes appear in the CSF between three and seven days after onset ${ }^{27}$ (table 3 ).

There are few published reports of necropsy studies in ischaemic stroke. One study of 11 patients who died between 15 hours and 18 days after ictus showed significant increases

Table 2 Possible causes of failure trials of clinical neuroprotection

Experimental demonstration of neuroprotection incomplete (functional end points?) Inappropriate agent: mechanism of action not relevant in humans*

Inappropriate dose of agent (plasma concentrations suboptimal either globally or in subgroups)

Target process not active in critical areas of pathophysiology (penumbra)

Efficacy limited by side effects that worsen outcome (for example, fever)

Inappropriate timing: mechanism of action not active at time of administration

Inappropriate or inadequate duration of treatment

Study population too sick to benefit

Study population too heterogeneous: efficacy only in an unidentifiable subgroup*

Study cohort too small to remove effect of confounding factors*

Failure of randomisation to distribute confounding factors evenly*

Insensitive, inadequate, or poorly implemented outcome measures

*May benefit from small mechanistic studies in homogeneous well characterised clinical subgroups. Adapted from Menon et al. ${ }^{17}$ 
Table 3 CSF and histological evidence for the cerebral recruitment of leucocytes in clinical stroke

\begin{tabular}{|c|c|c|c|c|c|}
\hline Reference & Stroke type & Analysis & Time scale & Results & Comments \\
\hline $\begin{array}{l}\text { Sornas } \\
\text { et al, } \\
1972^{27}\end{array}$ & $\begin{array}{l}\text { Ischaemic stroke } \\
\text { (embolic and } \\
\text { thrombotic, } \\
n=110 \text { ), and } \\
\text { primary } \\
\text { haemorrhagic } \\
\text { stroke }(n=16 \text { ) }\end{array}$ & $\begin{array}{l}\text { Consecutive } \\
\text { cellular CSF } \\
\text { analysis }\end{array}$ & $\begin{array}{l}\text { Longitudinal; } \\
1-3 \text { day } \\
\text { intervals up to } \\
4 \text { weeks }\end{array}$ & $\begin{array}{l}\text { Significant } \\
\text { neutrophils } \\
\text { detected in 25\% } \\
\text { of ischaemic } \\
\text { cases }\end{array}$ & $\begin{array}{l}\text { Repeat LP may influence } \\
\text { results; ischaemia } \\
\text { neutrophil } \\
\text { density< haemorrhage } \\
\text { neutrophil density; later } \\
\text { peak in macrophage } \\
\text { density; presence of } \\
\text { collaterals may influence } \\
\text { neutrophil density in } \\
\text { ischaemic cases }\end{array}$ \\
\hline $\begin{array}{l}\text { Chuaqui } \\
\text { and Tapia, } \\
1993^{28}\end{array}$ & $\begin{array}{l}\text { Non-haemorrhagic } \\
(n=16) \text { and } \\
\text { haemorrhagic } \\
\text { infarcts }(n=15)\end{array}$ & $\begin{array}{l}\text { Histology } \\
\text { (variety of } \\
\text { stains) from } \\
\text { core and } \\
\text { margins, } \\
\text { anterior and } \\
\text { posterior } \\
\text { circulations }\end{array}$ & $\begin{array}{l}16 \text { hours to } 27 \\
\text { days post-ictus }\end{array}$ & $\begin{array}{l}\text { Neutrophils seen } \\
\text { from day } 1 \text { and } \\
\text { absent by day } 8 \text {; } \\
\text { macrophages } \\
\text { from day } 5\end{array}$ & $\begin{array}{l}\text { No neutrophils detected } \\
\text { on day } 1 \text {; data on } \\
\text { leucocyte density core } v \\
\text { margin not presented; } \\
\text { more persistent neutrophil } \\
\text { and later macrophage } \\
\text { response and in } \\
\text { haemorrhagic } v \text { non- } \\
\text { haemorrhagic infarction }\end{array}$ \\
\hline $\begin{array}{l}\text { Lindsberg } \\
\text { et al, } \\
1996^{29}\end{array}$ & $\begin{array}{l}\text { Ischaemic stroke } \\
(n=11)\end{array}$ & $\begin{array}{l}\text { Histology } \\
\text { (H\&E stain); } \\
\text { core and } \\
\text { margin } \\
\text { delineated on } \\
\text { basis of } \\
\text { neuronal } \\
\text { damage }\end{array}$ & $\begin{array}{l}15 \text { hours to } 18 \\
\text { days post-ictus }\end{array}$ & $\begin{array}{l}\text { Neutrophils } \\
\text { detected in } \\
\text { infarcted regions } \\
\text { from } 15 \text { hours }\end{array}$ & $\begin{array}{l}\text { Normalised density } \\
\text { neutrophils by } 6 \text { days; } \\
\text { macrophages seen at } 17 \\
\text { days; no statistical } \\
\text { analysis on severe } v \text { mild } \\
\text { damage areas with } \\
\text { respect to granulocyte and } \\
\text { monocyte densities }\end{array}$ \\
\hline
\end{tabular}

$H \& E$, haematoxylin and eosin; LP, lumbar puncture.

in the density of granulocytes in cerebral microvessels of the most acute patients (table 6). ${ }^{29}$ Specifically, neutrophils have been demonstrated from day 1 , and appeared most numerous on days 2 and 3 following clinical onset. Macrophages appeared on day 5 and seem most abundant in the third week. ${ }^{28}$ The accumulation of leucocytes does not secure a causal relation (where animal interventional studies have provided stronger evidence), but may instead represent a marker of injury. There are no data on lymphocyte brain recruitment following clinical stroke.

\section{Imaging white cell responses in human stroke}

While postmortem histology provides concrete evidence of leucocyte recruitment to the ischaemic brain, it cannot provide longitudinal data in individual subjects. Serial samples of blood or CSF do allow us to study temporal patterns, but only indirectly. There is a clear requirement to study temporal changes in leucocyte recruitment, and elucidate the spatial distribution between the stroke core and the penumbra. Well developed methodology in this area would not only allow us to document pathophysiology, but may also provide an accessible surrogate end point for the preliminary assessment of interventions aimed at inhibiting leucocyte recruitment in stroke.

Initial in vivo imaging evidence for white cell accumulation in human cerebral infarction came from radiolabelled ${ }^{111}$ indium $\left({ }^{111} \mathrm{In}\right)$ leucocyte SPECT studies, in which CTconfirmed stroke patients were scanned between 48 hours and two weeks after symptom onset. Increased white cell tracer was detected in the infarcted hemisphere in seven of eight patients with crudely defined neurological deficit. ${ }^{30}$ This finding does not appear to be related to changes in the bloodbrain barrier or to free ${ }^{111}$ In in plasma. ${ }^{111}$ In was used to label all leucocyte subsets in that study. More recently, Wang et al used ${ }^{99 \mathrm{~m}}$ Tc-HMPAO SPECT to study non-specific leucocyte migration in acute and chronic ischaemic stroke. ${ }^{31}$ No infiltration was seen in early stroke, but significant leucocyte recruitment occurred up to five weeks post-onset, which was spatially correlated with areas of perfusion defect and associated with crudely defined poor neurological outcomes. Akopov et al used ${ }^{99 \mathrm{~m}} \mathrm{Tc}-\mathrm{HMPAO}$ SPECT to study the temporal pattern of recruitment of selectively labelled neutrophils following stroke. ${ }^{32}$ Neutrophil accumulation was first detected at six hours post-onset, peaking at 24 hours and remaining at high levels for up to nine days before declining. In addition, a correlation between the degree of leucocyte influx and functional outcome was observed. In vitro studies have suggested, however, that technetium may not be sufficiently stable for imaging leucocyte accumulation following stroke, predominantly on account of label elution from leucocytes. ${ }^{33}$ Furthermore, measurement of outcome using the Mathew scale is thought to have several limitations. ${ }^{34}$ Further studies showed similar leucocyte aggregation when using ${ }^{111} \mathrm{In}$ and mixed leucocytes, but only beyond 48 hours after clinical onset. ${ }^{35}$ SPECT with selective ${ }^{111}$ In labelling of neutrophils can be used to demonstrate extensive hemispheric invasion within 24 hours of onset (fig 1). While these results are interesting, the poor localisation provided by SPECT dictates that the specific localisation of inflammation to penumbral regions is likely to require new markers and other techniques. One potential method of achieving this objective is to use positron emission tomography (PET). The PET ligand ${ }^{11} \mathrm{C}$-PK11195 binds to a subset of peripheral $(\varphi 3)$ mitochondrial benzodiazepine receptors that are found both in astrocytes and on inflammatory cells-namely (and in order of binding affinity), macrophages/activated microglia, granulocytes, and to a lesser extent lymphocytes. ${ }^{36-39}$ Under a variety of experimental CNS pathological conditions, for example facial nerve axotomy, binding of PK11195 appears to be relatively specific to microglia, ${ }^{40}$ while in others a degree of astrocyte binding is noted. ${ }^{41}$ In experimental cerebral ischaemia in primates, upregulation of such receptor binding has been demonstrated in the infarcted hemisphere, most prominently in a rim of peri-infarct tissue from one to six weeks, although precise cellular localisation in this, and other studies, was not undertaken. ${ }^{39} 42$ In clinical ischaemic stroke, three key studies have indicated that such a ligand may provide further insights. Junck et $\mathrm{al}^{43}$ in an article published 

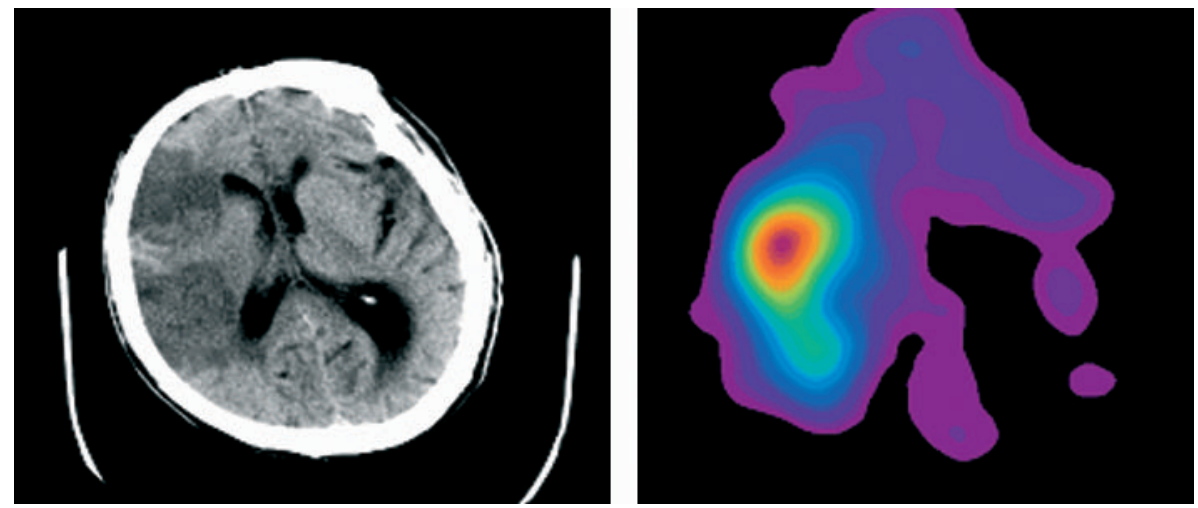

Figure 1 Computed tomogram at 16 hours and corresponding autologous indium labelled neutrophil scan at 36 hours following clinical onset of a right total anterior circulation ischaemic stroke. The area of high indium signal correlates anatomically with the area of infarction in a large proportion of the right middle cerebral artery.

only in abstract form, found increased signal within the infarct that decreased with time in a series of six patients eight to 55 days after clinical onset; enhanced activity was thought to represent binding to the peripheral type benzodiazepine binding site (PBBS). A further study in a single patient with stroke after coronary artery bypass grafting showed binding at 13 and 20 but not at six days post-onset. ${ }^{44}$ Finally, the Ulm group confirmed absence of binding at five days, while subsequent binding extending beyond the margin of the stroke was suggested. ${ }^{45}$ That study did not yield outcome data, and conclusions drawn from it rest fundamentally on the presumption that the in vivo presence of microglia reflects functional activation of these cells.

While PK11195 allows access to the exquisite sensitivity provided by PET, one problem is its lack of specificity in imaging the various cell types involved in neuroinflammation following stroke. Thus increases in PK11195 binding in the brain following stroke have been often interpreted as microglial activation, ${ }^{40}{ }^{46}$ but there is the theoretical possibility that this upregulation may represent granulocytes. Dissection of the cellular phenotypes involved at different stages following ischaemic injury is an important first step in the rational design, application, and assessment of novel anti-inflammatory interventions. For example, anti-adhesion treatments aimed at endothelial leucocyte trafficking are unlikely to be effective if the dominant cells involved in the process are resident microglia. Such specificity can only be achieved by the design of more selective PET ligands, or the use of ex vivo labelling of specific cell subpopulations with amphiphilic radioligands, for example ${ }^{64} \mathrm{Cu}$-ATSM.

\section{CHEMOKINES}

Evidence for a robust immune response in pathological states in brain ischaemia relates not only to endothelial and peripheral leucocyte activation, but also to a complex cascade of humoral factors involving both cytokines and chemokines. These molecules have a diverse set of functions, proinflammatory, immunosuppressant, and a combination of the two. Furthermore, their function extends beyond a purely chemokinetic role to properties more applicable to growth factors. Such molecules may be secreted in response to a variety of stimuli, not only for the purposes of regulation of other cellular functions but also for self feedback. This group of molecules forms an important arm of the integrated inflammatory process that follows acute cerebral ischaemia (fig 2).

In the acute inflammatory response, neutrophils are thought to extravasate early, involving a process of rolling, activation, arrest/adhesion, and transmigration. Chemokines appear to activate neutrophils by binding to receptors, inducing conformational changes in integrin molecules that in turn augment adhesion and transmigration.

There is now a large body of (mainly) experimental evidence for the pathological involvement of both interleukin-1 (IL-1) and tumour necrosis factor $\alpha$ (TNF $\alpha$ ) in the aetiology of acute cerebral ischaemia, with supportive roles for other cytokines. While there remains little doubt as to the involvement of such molecules, their mechanism of action may be more diverse than originally thought and this remains an area under intense investigation. Such evidence is more extensively reviewed elsewhere. ${ }^{611} 13$ There remain several other molecules that may play an instrumental role in the cellular neuroinflammatory response, in particular chemokines (table 4). In particular, we have focused on chemokines known to be involved in neutrophil and monocyte/macrophage recruitment, as derived from a variety of experimental models. ${ }^{47-54}$ Their role in the recruitment of leucocytes within the context of acute clinical ischaemic stroke is reviewed here and summarised in table 5 .

\section{Chemokine responses in clinical stroke and cerebral ischaemia}

Peripheral chemokine responses

Extrapolating from experimental work, ${ }^{49}$ IL-8, in addition to emerging physiological roles in neurodevelopment and physiological signalling, ${ }^{59}$ appears to be a key contender in the pathological arena of leucocyte recruitment. Levels of IL-8 mRNA in neutrophil and peripheral monocyte populations in ischaemic stroke were significantly higher than in controls up to seven days post-ictus. This contrasts with other molecules such as macrophage inflammatory protein (MIP)- $1 \alpha$, thought to be an important mediator of monocyte/macrophage accumulation, over the same time period..$^{55}$ The CD11b/CD18 neutrophil surface adhesion molecule expression on human neutrophils is upgraded in response to exposure to IL-8, suggesting that IL- 8 is linked to cellular chemotactic mechanisms in vivo. ${ }^{61}$ While such data support a proinflammatory cellular activation in stroke, they do not localise such processes to the injured brain.

\section{CSF chemokine responses}

Plasma and CSF concentrations of IL-8 and peripheral monocyte levels of IL-8 mRNA expression increase one to three days after ischaemic stroke, and peripheral numbers of monocytes expressing IL-8 mRNA appeared to correlate with outcome in a group of 18 patients assessed on the Scandinavian stroke scale. ${ }^{60}$ In another study, CSF levels of IL-8 were significantly greater than controls in early stroke, and peaked on day 2 post-ictus; CSF levels were particularly 


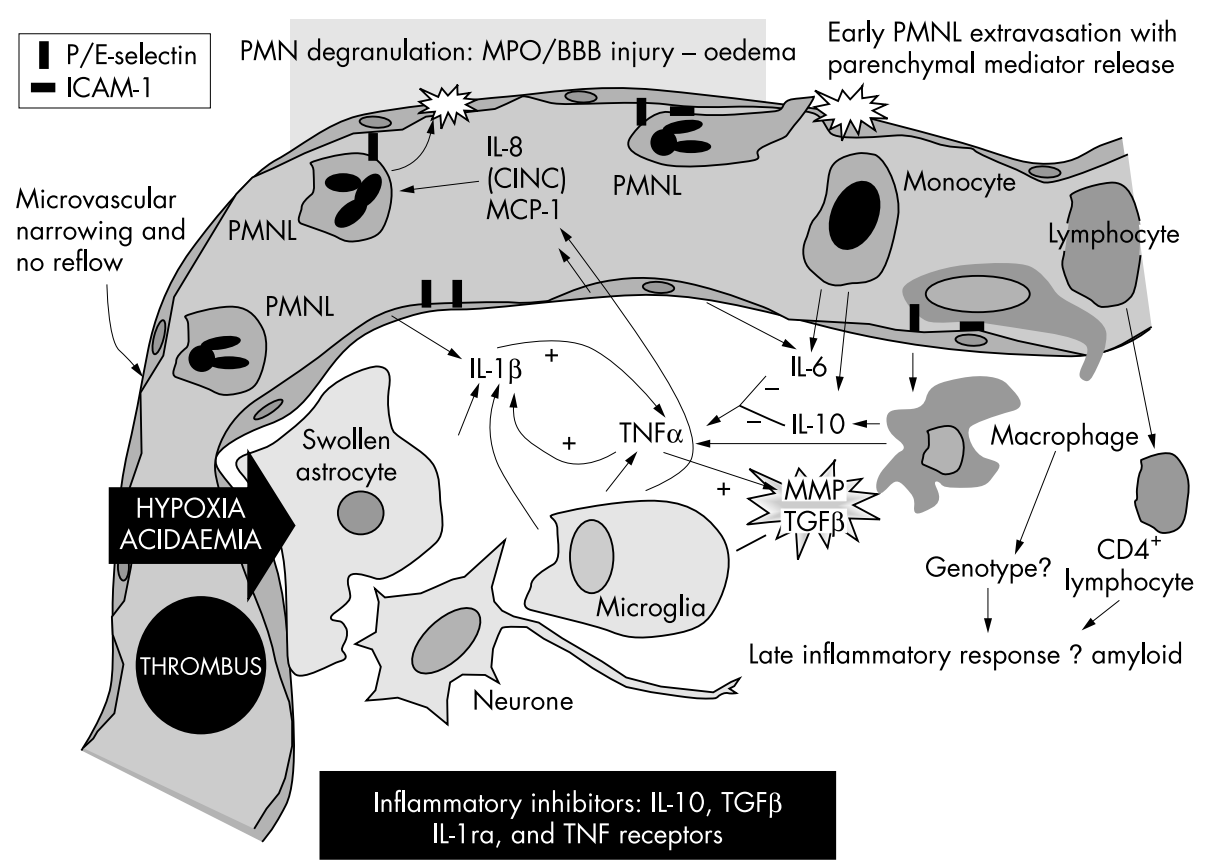

Figure 2 Schematic diagram of inflammatory responses in acute ischaemic stroke. BBB, blood-brain barrier; ICAM, intercellular adhesion molecule; IL, interleukin; MCP, monocyte chemoattractant protein; MMP, matrix metalloproteinase; PMNL, polymorphonuclear leucocyte; TGF, transforming growth factor; TNF, tumour necrosis factor; + , inducer; - , inhibitor. Adapted from Menon and Summors. ${ }^{17}$

high in patients in whom disease was confined to white matter. ${ }^{56}$ More recently, raised levels of monocyte chemoattractant protein (MCP)-1, also involved in macrophage recruitment, have been reported in CSF 24 hours after ischaemic stroke, while CSF levels (which may represent autochthonous CNS production) are not matched by corresponding levels in plasma. ${ }^{58}$

\section{Chemokine responses in other forms of acute} ischaemic brain injury

Chemokines may also play a role in other forms of acute brain injury where ischaemia can be a component. Raised concentrations of IL-8 in CSF have been found following traumatic brain injury in children, ${ }^{62}$ and positive arteriojugular gradients for this mediator have been demonstrated in head injury and following cardiopulmonary bypass. ${ }^{57}$ Cisternal levels of IL-8 are also grossly increased after subarachnoid haemorrhage, and may be particularly raised in patients who undergo early aneurysm surgery (within 72 hours) in comparison to surgery at a later date. ${ }^{63}$

\section{Other chemoattractant molecules}

In this review we have focused mainly on chemokine responses in stroke, and have provided most data on IL-8. Other chemokines and non-chemokine attractant molecules such as prostanoids, leukotrienes, and complement frag-

Table 4 Chemokine groups relevant to inflammation after cerebral ischaemia

\begin{tabular}{ll}
\hline Group & Molecule \\
\hline C-C group & MIP-1, 5, MCP-1, 2, 3, RANTES, SLC \\
C-X-C group & IL-8, IP-10, CINC \\
\hline
\end{tabular}

CINC, cytokine induced neutrophil chemoattractant; IL, interleukin; IP, interferon inducible protein; MCP, monocyte chemoattractant protein; MIP, macrophage inflammatory protein; RANTES, regulated on activation normal T cell expressed and secreted; SLC, secondary lymphoid tissue chemokine. ments are known to be involved in leucocyte recruitment in inflammation. However, there are no data addressing these molecules in the context of clinical stroke, and the data are limited even in the setting of experimental models. It is important to recognise that any of these molecules may play a role in leucocyte recruitment, and further studies are needed. ${ }^{4} 106465$

\section{ADHESION MOLECULES}

Endothelial expression of cellular adhesion molecules (CAM) forms part of a complex interaction of immune pathways that contribute to inflammation in cerebral ischaemia. Such interactions present potential therapeutic targets, some of which have been explored in experimental settings. Adhesion molecules, which are important in the context of cellular inflammation in acute ischaemic stroke, may be categorised in terms of the cells that express the molecule, the cells targeted for adhesion, or in the chronological order in which they are expressed. They are classified according to their molecular structure (for example, heterodimeric proteins such as integrins) or in relation to their functional domain (for example, the immunoglobulin superfamily such as intercellular adhesion molecules (ICAM)). A classification of adhesion molecules is given in table 6. Several CAMs are expressed constitutively-for example, P-selectin on endothelium-and may in some be inducible by cytokines (IL-1 may upregulate endothelial expression of ICAM-1). ${ }^{66}$ The selectin group of molecules are pivotal in the early rolling effect, while the immunoglobulin and $\beta 2$ integrin families appear to play a more prominent role in adhesion and transmigration. ${ }^{16}$

\section{Adhesion molecule responses in clinical stroke}

Clinical data on adhesion molecule responses in cerebral ischaemia are limited when compared with experimental studies. Several studies provide useful data in this setting, using histological examination of postmortem brain and measurement of circulating levels of soluble adhesion molecules (shed from sites of expression); the precise relation 


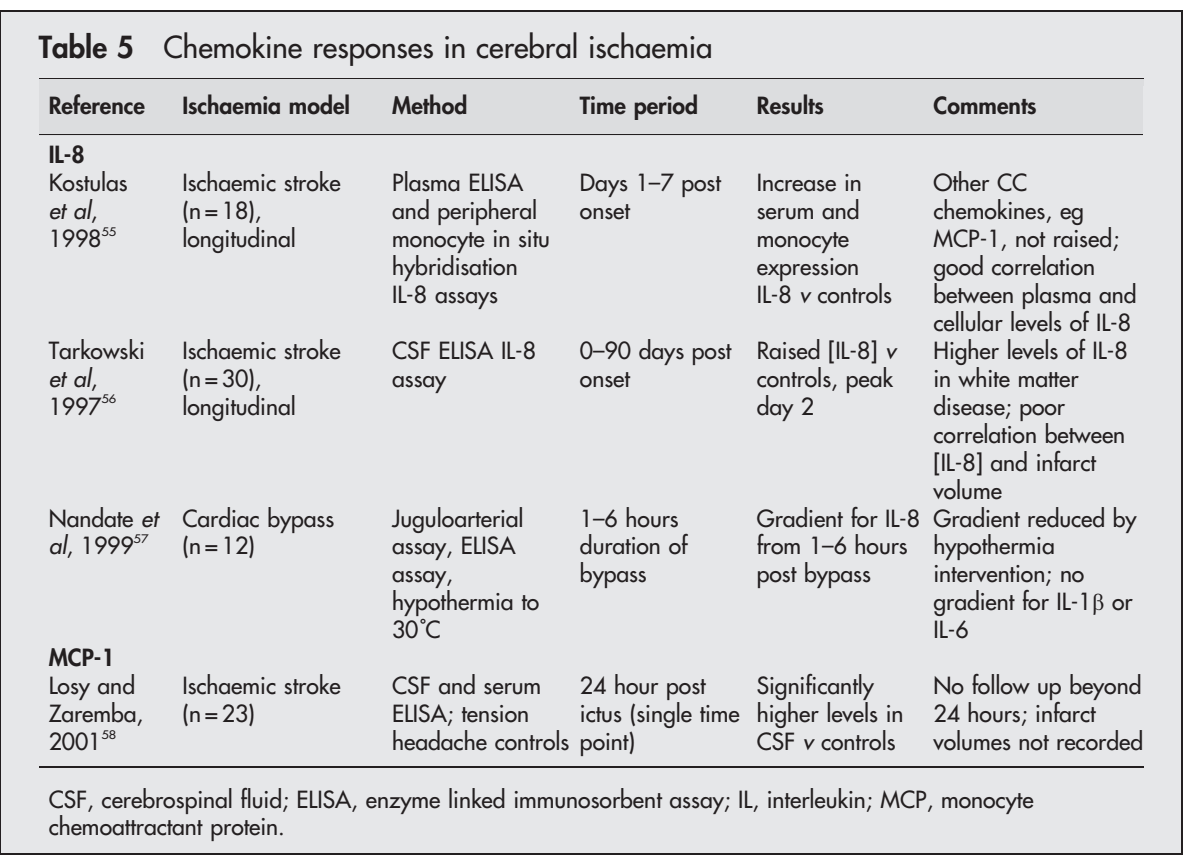

between such circulating molecules and their bioactive bound counterparts remains to be established. The data are summarised in table 7 .

\section{Postmortem histology}

Lindsberg et al investigated ICAM-1 expression in ischaemic stroke postmortem brain tissue (where death was caused by brain oedema, pulmonary embolism, or cardiac failure), using immunocytochemistry. In the earliest sample, at 15 hours after clinical onset, ICAM-1 expression within the infarct was significantly greater than in corresponding control hemisphere. ${ }^{29}$ Other studies have shown enhanced astrocyte expression of VCAM-1 in samples of brain tissue of ischaemic stroke patients nine to 10 days after clinical onset (patients who died as a result of their stroke), with such expression localising to the edge of ischaemic lesions. ${ }^{75}$

\section{Soluble adhesion molecules in peripheral blood}

Several studies have compared levels of circulating adhesion molecules in ischaemic stroke, transient ischaemic attacks (TIA), and volunteers with vascular risk factors. In addition to telling us relatively little about cerebral mechanisms, such studies often fail to control for confounding factors often seen in hospital inpatients. The results of such studies are summarised in table 6 .

Where ischaemic stroke and TIA are compared, an increase of CDIla expression on neutrophils is seen within 72 hours of clinical onset, while such changes only achieved significance in the TIA group. ${ }^{61}$ Further evidence of peripheral leucocyte activation in stroke is provided by increased CDI8 levels on peripheral leucocytes 12 hours after clinical onset. ${ }^{70}$

In ischaemic stroke, there is evidence that peripheral levels of circulating soluble ICAM-1 (sICAM-1) are significantly lower, and concurrent neutrophil adherence assays significantly higher, than in controls. ${ }^{67}$ This contrasts with other studies where no increases of SICAM-1 was recorded within the context of stroke or recent carotid endarterectomy (summarised in table 7) ${ }^{69}$ Other investigators have reported on circulating adhesion molecule concentrations both in patients at risk of a stroke and in those with established infarction. In the at-risk group, raised SICAM-1 was noted, whereas sE-selectin was similar to controls; in ischaemic stroke patients, levels of sE-selectin rose early and transiently, with a later and more persistent rise in sICAM- $1 .{ }^{71}$ In patients with ischaemic stroke and in those with symptomatic carotid artery stenosis giving rise to transient or

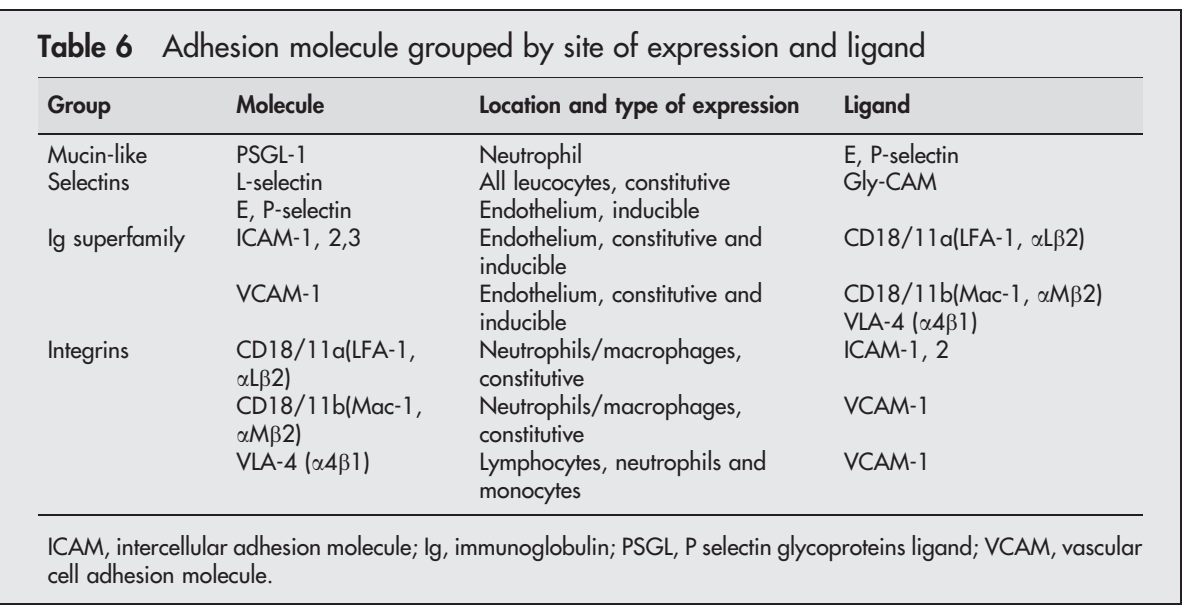




\begin{tabular}{|c|c|c|c|c|}
\hline Reference & Model/group & Time period/method & Results & Comments \\
\hline \multicolumn{5}{|c|}{ ICAM-1 (see also ${ }^{29}$ in table 3 ) } \\
\hline $\begin{array}{l}\text { Clark et al, } \\
1993^{67}\end{array}$ & $\begin{array}{l}\text { Ischaemic stroke and } \\
\text { volunteers }(n=39) \\
\text { with risk factors, eg } \\
\text { hypertension, diabetes }\end{array}$ & $\begin{array}{l}<72 \text { hours post } \\
\text { clinical onset } \\
\text { (ischaemic stroke); } \\
\text { soluble plasma ICAM-1 } \\
\text { (sICAM-1) assay; MPO } \\
\text { based assay for } \\
\text { neutrophil adherence }\end{array}$ & $\begin{array}{l}\text { Low sICAM-1 and } \\
\text { increased neutrophil } \\
\text { adhesion in stroke } \\
\text { group }\end{array}$ & $\begin{array}{l}\text { Non-longitudinal } \\
\text { data }\end{array}$ \\
\hline $\begin{array}{l}\text { Kim et al, } \\
1995^{68}\end{array}$ & $\begin{array}{l}\text { Ischaemic stroke } \\
(n=10) \text { and TIA } \\
(n=6)\end{array}$ & $\begin{array}{l}<72 \text { hours post clinical } \\
\text { onset; peripheral } \\
\text { leucocyte CD } 11 \mathrm{a} / \mathrm{CD} 18 \\
\text { immunofluorescence; } \\
\text { repeat measurements } \\
\text { up to } 7 \text { days }\end{array}$ & $\begin{array}{l}\text { CD-1 la raised in both } \\
\text { stroke and TIA } v \\
\text { controls }\end{array}$ & $\begin{array}{l}\text { CD18 raised only in } \\
\text { TIA group; relation } \\
\text { between peripheral } \\
v \text { cerebral activation } \\
\text { unclear }\end{array}$ \\
\hline $\begin{array}{l}\text { Friins et al, } \\
1997^{69}\end{array}$ & $\begin{array}{l}\text { Ischaemic stroke } \\
(n=28) \text { and TIA } \\
(n=34) \text { due to } \\
\text { symptomatic ICA } \\
\text { stenosis and controls } \\
(n=34)\end{array}$ & $\begin{array}{l}<2 \text { days post ischaemic } \\
\text { stroke; }>1 \text { week post } \\
\text { TIA; plasma soluble } \\
\text { ICAM-1 and VCAM-1 } \\
\text { ELISA; single } \\
\text { measurement }\end{array}$ & $\begin{array}{l}\text { Soluble ICAM-1 not } \\
\text { raised; soluble } \\
\text { VCAM-1 significantly } \\
\text { raised }\end{array}$ & $\begin{array}{l}\text { Selectin group also } \\
\text { raised in ischaemic } \\
\text { stroke and TIA } v \\
\text { controls }\end{array}$ \\
\hline $\begin{array}{l}\text { Fiszer et al, } \\
1998^{70}\end{array}$ & $\begin{array}{l}\text { Ischaemic stroke } \\
(n=20)\end{array}$ & $\begin{array}{l}12 \text { hours post onset } \\
\text { and } 7 \text { and } 30 \text { days; } \\
\text { immunofluorescence } \\
\text { and flow cytometry of } \\
\text { CD1 la, b, and } 18\end{array}$ & $\begin{array}{l}\text { CD18 } \\
\text { immunofluorescence } \\
\text { increased after } 12 \text { hours }\end{array}$ & $\begin{array}{l}\text { Normalised CDI la } \\
\text { and b } \\
\text { immunofluorescence } \\
\text { by day } 7 \text {; ischaemic } \\
\text { stroke patients had } \\
\text { higher peripheral } \\
\text { leucocyte counts }\end{array}$ \\
\hline \multicolumn{5}{|l|}{ Selectin } \\
\hline $\begin{array}{l}\text { Fassbender } \\
\text { et al, } 1995^{71}\end{array}$ & $\begin{array}{l}\text { Ischaemic stroke } \\
\text { ( } n=22) \text {, controls } \\
\text { with risk factors (RF, } \\
n=40) \text { and without } \\
\operatorname{RF}(n=22)\end{array}$ & $\begin{array}{l}\text { Ischaemic stroke: }<4 \\
\text { hours post clinical onset } \\
\text { and serial measurements } \\
\text { to day 5; soluble } \\
\text { ELAM-1, L-selectin and } \\
\text { ICAM-1 in serum }\end{array}$ & $\begin{array}{l}\text { In ischaemic stroke } v \text { RF: } \\
\text { high levels of } s \text {-ELAM-1 } \\
\text { until day } 1 \text {; sL-selectin } \\
\text { not raised over controls }\end{array}$ & $\begin{array}{l}\text { RF } v \text { no RF controls: } \\
\text { high sICAM-1 but } \\
\text { not sVCAM-1 or } \\
\text { sELAM-1 }\end{array}$ \\
\hline $\begin{array}{l}\text { Shyu et al, } \\
1997^{72}\end{array}$ & $\begin{array}{l}\text { Ischaemic stroke }+/- \\
\text { carotid stenosis } \\
(n=51) \vee \text { controls }\end{array}$ & $\begin{array}{l}<24 \text { hours post clinical } \\
\text { onset; serum ELISA for } \\
\text { E-selectin; single } \\
\text { measurement }\end{array}$ & $\begin{array}{l}\text { No increase in E-selectin } \\
\text { in acute stroke }\end{array}$ & $\begin{array}{l}\text { ICAM-1 levels } \\
\text { increased in } \\
\text { ischaemic stroke; } \\
\text { presence of stenosis } \\
\text { did not influence } \\
\text { levels of either } \\
\text { molecule }\end{array}$ \\
\hline $\begin{array}{l}\text { Stanimirovic } \\
1997^{73}\end{array}$ & $\begin{array}{l}\text { In vitro ischaemia } \\
\text { and cytokine } \\
\text { stimulation of human } \\
\text { endothelium in culture }\end{array}$ & $\begin{array}{l}\text { Exposure to IL-1 } \beta / T N F \alpha \\
\text { or } 4-24 \text { hours } \\
\text { ischaemia; ELISA/ } \\
\text { immunohistochemistry } \\
\text { for ICAM-1, VCAM-1 } \\
\text { and E-selectin }\end{array}$ & $\begin{array}{l}\text { ICAM-1, E-selectin and } \\
\text { VCAM-1 all upgraded }\end{array}$ & $\begin{array}{l}\text { Indomethacin and } \\
\text { actinomycin D } \\
\text { reduced adhesion } \\
\text { molecule expression }\end{array}$ \\
\hline Bitsch $1998^{74}$ & $\begin{array}{l}\text { Ischaemic stroke and } \\
\text { TIA ( } n=38)\end{array}$ & $\begin{array}{l}\text { 0-14 days post clinical } \\
\text { onset; serum ELISA } \\
\text { assays of adhesion } \\
\text { molecules }\end{array}$ & $\begin{array}{l}\text { Expression of E-selectin } \\
\text { raised in ischaemic } \\
\text { stroke } v \text { TIA, peak at } 5 \\
\text { days; sICAM-1 and } \\
\text { sVCAM-1 raised and } \\
\text { peak at } 24 \text { hours and } 5 \\
\text { days, respectively }\end{array}$ & $\begin{array}{l}\text { Control group not } \\
\text { defined; levels do } \\
\text { not correlate with } \\
\text { infarct volume or } \\
\text { disability }\end{array}$ \\
\hline \multicolumn{5}{|l|}{ VCAM } \\
\hline $\begin{array}{l}\text { Kaluza et al, } \\
1994^{75}\end{array}$ & $\begin{array}{l}\text { Ischaemic stroke } \\
(\mathrm{n}=3)\end{array}$ & $\begin{array}{l}\text { 9-10 days post clinical } \\
\text { onset; postmortem } \\
\text { immunostain with } \\
\text { monoclonal antibody }\end{array}$ & $\begin{array}{l}\text { VCAM- } 1 \text { +ve astrocytes } \\
\text { staining within infarct }\end{array}$ & $\begin{array}{l}\text { No staining outside } \\
\text { ischaemic area }\end{array}$ \\
\hline
\end{tabular}

ELSA, enzyme linked immunosorbent assay; ICAM, intercellular adhesion molecule; MPO, myeloperoxidase; TIA, transient ischaemic attack; VCAM, vascular cell adhesion molecule.

persistent neurological deficit, sE-selectin and sP-selectin were significantly raised when compared with controls. ${ }^{69}$ While such findings may suggest acute endothelial activation, platelet activation may also play a part. These findings are in contrast to a study where no peripheral increase in Eselectin was found in acute ischaemic stroke compared with age matched controls. ${ }^{72}$ Such contradictory results probably reflect uncertainty about the precise relation between endothelial and soluble forms of these molecules. In longitudinal studies, selectins and raised concentrations of soluble adhesion molecules have not been clearly correlated with outcome, although higher initial increases in sE-selectin were seen in more disabled patients.

\section{INTERVENTIONAL STUDIES}

The demonstration that inflammatory processes have a pathogenic role is dependent on showing improvement in outcome by treatment that antagonise these processes. Different parts of the inflammatory cascade have been targeted in the setting of experimental cerebral ischaemia, with variable results.

\section{Anti-inflammatory interventions in clinical stroke}

While there are some data relating to transmigration of leucocytes in other forms of CNS injury, ${ }^{76}$ these are limited with respect to corticosteroid interventions in cerebral ischaemia. $^{78}$ Furthermore, direct and pertinent data on 
cerebral neutrophil or monocyte/macrophage recruitment and function are not abundant in this context. ${ }^{79}$ In part this may explain why relatively few clinical trials involving immunomodulation have been carried out in human acute stroke. The Cochrane Collaboration reviewed seven published randomised controlled trials of corticosteroid treatment in acute stroke and found no odds ratio reduction in death at one year or improvement in functional outcome when treatment was begun less than 48 hours after onset. ${ }^{80}$ While the evidence that leucocytes contribute to ischaemia in stroke is strong, the mechanism is less clear and has prompted interest in humoral and endothelial factors that might influence or control the extent of such migration. Some limited application of adhesion molecule biology has been attempted in acute ischaemic stroke. Administration of a murine derived anti-ICAM to stroke patients within six hours of clinical onset (where haemorrhage was excluded), in a double blind placebo controlled trial, failed to demonstrate benefit. ${ }^{1}$ Indeed, treatment was associated with a significantly worse outcome. Initial explanations for this involved the administration of the murine antibody, a propensity to infection following systemic functional consumption of adhesion molecules, or the dose and method of administration. Comparison of this trial with others in non-acute disease remains difficult. Since then, this antibody has been shown to activate neutrophils in a complement dependent manner in whole blood at concentrations achieved in clinical trials. ${ }^{81}$ Where selective IgGl isotype monoclonal antibody or $\mathrm{F}(\mathrm{ab})^{\prime} 2$ fragments to ICAM-1 were given, neutrophil activation did not occur. Additional clinical trials, as yet unpublished, giving a CD11b/CD18 neutrophil antagonist (UK 279, 276) to patients with acute ischaemic stroke within six hours of onset have been stopped because of futility. ${ }^{2}$

\section{CONCLUSIONS AND FUTURE STRATEGY}

There is now much evidence for a cellular inflammatory component in the pathophysiology of acute stroke. This evidence, predominantly derived from controlled animal studies, relates to leucocytes and the molecular mechanisms involved in their recruitment. Evidence for such mechanisms in humans remains methodologically limited and broadly circumstantial, and a causal relation has yet to be established. Furthermore there is a growing body of evidence to suggest that atherosclerosis as a disease process may itself be driven by inflammation. ${ }^{82}$ Interventional studies contribute to our understanding of this relation but pose further questions.

Controlled animal experiments have not yet yielded unequivocally safe and effective treatment for human stroke. This has prompted the suggestion that such models cannot be formally extrapolated to patients, and that our understanding of human pathophysiology remains incomplete. At present we do not have enough evidence to suggest that human inflammatory processes mimic animal models, and this should prompt a greater drive towards patient based research. This point is illustrated by limited data where such extrapolation has been attempted. ${ }^{1}$ Although not directly comparable, similar immunological applications in chronic disease-for example, rheumatoid arthritis, where monoclonal antibodies to $\mathrm{TNF} \alpha$ appear to have disease modifying properties-provide hopeful prospects. ${ }^{83}$ There is also evidence to suggest that HMG-CoA reductase inhibitors (statins), which have a number of anti-inflammatory effects, may be able to inhibit leucocyte integrin function and hence offer a therapeutic addition to aspirin. ${ }^{84}$ Finally, the precise role of aspirin and other antiplatelet agents with respect to CNS leucocyte sequestration remains unclear.

Our understanding of how these processes contribute to cell death is far from complete, and although trials of various neuroprotective agents have been uniformly disappointing, the need for research in this area remains strong ${ }^{85}$-in particular, to establish precise temporal relations between components of the inflammatory response in vivo, and to correlate inflammatory changes more accurately with anatomy and outcome. Such studies should place emphasis on the early stages of pathology when interventions are more likely to result in neuronal salvage. In addition, they must account for inter-individual and temporal and spatial heterogeneity in stroke. An understanding of spatial heterogeneity in clinical stroke demands the use of imaging studies that addresses the kinetics of leucocyte recruitment following stroke; such studies will need to quantify inflammatory responses and should ideally examine critical relations between a several different variables-for example, white cell invasion, chemokine response, adhesion molecules, penumbra, and outcome. While such imaging studies may be difficult to achieve, the data that they provide are likely to be critical in informing the application of anti-inflammatory treatment. Given the clinical heterogeneity of stroke, a universal anti-inflammatory panacea may be a distant prospect. The focused use of specific interventions in defined subgroups may, however, serve to complement other treatment currently under development.

\section{ACKNOWLEDGEMENTS}

CJSP is funded by the Medical Research Council, UK, as an MRC clinical training fellow. EAW is supported by a PPP mid career fellowship.

\section{Authors' affiliations}

C J S Price, Department of Medicine, Addenbrooke's Hospital, Cambridge, UK

E A Warburton, Division of Stroke Medicine, Addenbrooke's Hospital D K Menon, Anaesthesia, University of Cambridge

Competing interests: none declared

\section{REFERENCES}

1 Investigators EAST. Use of anti-ICAM-1 therapy in ischemic stroke: results of the Enlimomab Acute Stroke Trial. Neurology 2001;57:1428-34.

2 Directory ST. ASTIN: acute stroke therapy by inhibition of neutrophils, 2003.www.strokecenter.org/trialsand www.corvas.com/press_releases.

3 Council MR. Neuroprotection in acute brain injury after trauma and stroke. Field Review, 1998.

4 del Zoppo G, Ginis I, Hallenbeck JM, et al. Inflammation and stroke: putative role for cytokines, adhesion molecules and iNOS in brain response to ischemia. Brain Pathol 2000;10:95-112.

5 Barone FC, Feuerstein GZ. Inflammatory mediators and stroke: new opportunities for novel therapeutics. J Cereb Blood Flow Metab 1999; 19:819-34

6 Stoll G, Jander S, Schroeter M. Inflammation and glial responses in ischemic brain lesions. Prog Neurobiol 1998:56:149-71.

7 Becker KJ. Inflammation and acute stroke. Curr Opin Neurol 1998; 1 1:45-9.

8 ladecola C, Alexander M. Cerebral ischaemia and inflammation. Curr Opin Neurol 2001; 14:89-94.

9 Arvin B, Neville LF, Barone FC, et al. The role of inflammation and cytokines in brain injury. Neurosci Biobehav Rev 1996;20:445-52.

10 Emsley HC, Tyrrell PJ. Inflammation and infection in clinical stroke. J Cereb Blood Flow Metab 2002;22:1399-419.

11 Rothwell NJ, Luheshi GN. Interleukin 1 in the brain: biology, pathology and therapeutic target. Trends Neurosci 2000;23:618-25.

12 Feuerstein GZ, Wang X, Barone FC. The role of cytokines in the pathology of stroke and neurotrauma. Neuroimmunomodulation 1998;5:143-59.

13 Zaremba J. Contribution of tumor necrosis factor alpha to the pathogenesis of stroke. Folia Morphol (Warsz) 2000;59:137-43.

14 Feverstein GZ, Wang X, Barone FC. Cytokines in brain ischemia-the role of TNA alpha. Cell Mol Neurobiol 1998;18:695-701.

15 Pantoni L, Sarti C, Inzitari D. Cytokines and cell adhesion molecules in cerebral ischemia: experimental bases and therapeutic perspectives. Arterioscler Thromb Vasc Biol 1998;18:503-13.

16 Frijns CJ, Kappelle $\amalg$. Inflammatory cell adhesion molecules in ischemic cerebrovascular disease. Stroke 2002;33:2115-22.

17 Menon DK, Summors AC. Neuroprotection (including hypothermia). Curr Opin Anaethesiol 1998;11:495-6.

18 Prentice RL, Szatrowski TP, Kato H, et al. Leukocyte counts and cerebrovascular disease. J Chron Dis 1982;35:703-14. 
19 Noto D, Barbagallo CM, Cavera G, et al. Leukocyte count, diabetes mellitus and age are strong predictors of stroke in a rural population in southern ltaly: an 8-year follow-up. Atherosclerosis 2001;157:225-31.

$20 X_{U}$ YB, Zhu JS, Zhang GP. Activation and free radical formation of leukocytes in patients with acute ischemic stroke. Chung Hua Nei Ko Tsa Chih 1994;33:799-802.

21 Suzuki S, Kelley RE, Reyes-Iglesias Y, et al. Cerebrospinal fluid and peripheral white blood cell response to acute cerebral ischemia. South Med $J$ 1995:88:819-24.

22 Grau AJ, Berger E, Sung KL, et al. Granulocyte adhesion, deformability, and superoxide formation in acute stroke. Stroke 1992;23:33-9.

23 Galante A, Pietroiusti A, Magrini A, et al. Serial determinations of leukocyte aggregation in patients with ischemic stroke. Int J Neurosci 1993:73:69-76.

24 Galante A, Silvestrini M, Stanzione $P$, et al. Leucocyte aggregation in acute cerebrovascular disease. Acta Neurol Scand 1992;86:446-9.

25 Chang RR, Chien NT, Chen CH, et al. Spontaneous activation of circulating granulocytes in patients with acute myocardial and cerebral diseases. Biorheology 1992;29:549-61.

26 Grau AJ, Graf T, Hacke W. Altered influence of polymorphonuclear leukocytes on coagulation in acute ischemic stroke. Thromb Res 1994;76:541-9.

27 Sornas R, Ostlund H, Muller R. Cerebrospinal fluid cytology after stroke. Arch Neurol 1972;26:489-501.

28 Chuaqui R, Tapia J. Histologic assessment of the age of recent brain infarcts in man. J Neuropathol Exp Neurol 1993:52:481-9.

29 Lindsberg PJ, Carpen O, Paetau A, et al. Endothelial ICAM-1 expression associated with inflammatory cell response in human ischemic stroke. Circulation 1996;94:939-45.

30 Pozzilli C, Lenzi GL, Argentino C, et al. Imaging of leukocytic infiltration in human cerebral infarcts. Stroke 1985;16:251-5.

31 Wang PY, Kao CH, Mui MY, et al. Leukocyte infiltration in acute hemispheric ischemic stroke [see comments]. Stroke 1993;24:236-40.

32 Akopov SE, Simonian NA, Grigorian GS. Dynamics of polymorphonuclear leukocyłe accumulation in acute cerebral infarction and their correlation with brain tissue damage. Stroke 1996;27:1739-43.

33 Peters AM, Lavender JP. Imaging inflammation with radiolabelled white cells: 99Tcm-HMPAO or $111 \mathrm{ln}$ ? [editorial]. Nucl Med Commun 1991;12:923-5.

34 Wade DT. Measurement in neurological rehabilitation. Oxford: Oxford University Press, 1992:293.

35 Fujinuma K, Sakai F, lizuka T, et al. In-111-labeled leukocyte brain SPECT imaging in acute ischemic stroke in man. Rinsho Shinkeigaku 1997;37:13-20.

36 Syapin PJ, Skolnick P. Characterization of benzodiazepine binding sites in cultured cells of neural origin. J Neurochem 1979;32:1047-51.

37 Benavides J, Cornu P, Dennis T, et al. Imaging of human brain lesions with an omega 3 site radioligand. Ann Neurol 1988;24:708-12

38 Canat $X$, Carayon $P$, Bouaboula M, et al. Distribution profile and properties of peripheral-type benzodiazepine receptors on human hemopoietic cells. Life Sci 1993;52:107-18.

39 Sette G, Baron JC, Young AR, et al. In vivo mapping of brain benzodiazepine receptor changes by positron emission tomography after focal ischemia in the anesthetized baboon. Stroke 1993:24:2046-57; discussion 2057-8.

40 Banati RB, Myers R, Kreutzberg GW. PK ("peripheral benzodiazepine")binding sites in the CNS indicate early and discrete brain lesions: microautoradiographic detection of $\left[{ }^{3} \mathrm{H}\right] \mathrm{PK} 11195$ binding to activated microglia. J Neurocytol 1997;26:77-82.

41 Raghavendra Rao VL, Dogan A, Bowen KK, et al. Traumatic brain injury leads to increased expression of peripheral-type benzodiazepine receptors, neuronal death, and activation of astrocytes and microglia in rat thalamus. Exp Neurol 2000;161:102-14.

42 Rao VL, Bowen KK, Rao AM, et al. Up-regulation of the peripheral-type benzodiazepine receptor expression and $[(3) \mathrm{H}] \mathrm{PK} 11195$ binding in gerbil hippocampus after transient forebrain ischemia. J Neurosci Res 2001;64:493-500.

43 Junck L, Jewett D, Kilbourn M. PET imaging of cerebral infarcts using a ligand for peripheral benzodiazepine-biding site. Neurology 1990;40:265.

44 Ramsay SC, Weiller C, Myers R, et al. Monitoring by PET of macrophage accumulation in brain after ischaemic stroke [letter]. Lancet 1992;339: 1054-5.

45 Gerhard A, Neumaier B, Elitok E, et al. In vivo imaging of activated microglia using [ $\left.{ }^{11} \mathrm{C}\right] \mathrm{PK} 11195$ and positron emission tomography in patients after ischemic stroke [In Process citation]. Neuroreport 2000; 1 1:2957-60.

46 Stephenson DT, Schober DA, Smalstig EB, et al. Peripheral benzodiazepine receptors are colocalized with activated microglia following transient global forebrain ischemia in the rat. $J$ Neurosci 1995; 15:5263-74.

47 Zhang W, Smith C, Shapiro A, et al. Increased expression of bioactive chemokines in human cerebromicrovascular endothelial cells and astrocytes subjected to simulated ischemia in vitro. J Neuroimmunol 1999;101:148-60.

48 Sekido N, Mukaida N, Harada A, et al. Prevention of lung reperfusion injury in rabbits by a monoclonal antibody against interleukin-8. Nature 1993;365:654-7

49 Mukaida N, Matsumoto T, Yokoi K, et al. Inhibition of neutrophil-mediated acute inflammation injury by an antibody against interleukin-8 (IL-8). Inflamm Res 1998;47(suppl 3):S151-7

50 Gerszten RE, Garcia-Zepeda EA, Lim YC, et al. MCP-1 and IL-8 trigger firm adhesion of monocytes to vascular endothelium under flow conditions. Nature 1999:398:718-23.

51 Wang X, Yue TL, Barone FC, et al. Monocyte chemoattractant protein-1 messenger RNA expression in rat ischemic cortex. Stroke 1995;26:661-5; discussion 665-6.
52 Che X, Ye W, Panga L, et al. Monocyte chemoattractant protein-1 expressed in neurons and astrocytes during focal ischemia in mice. Brain Res 2001;902:171-7

53 Takami S, Nishikawa H, Minami M, et al. Induction of macrophage inflammatory protein MIP-lalpha mRNA on glial cells after focal cerebral ischemia in the rat. Neurosci Lett 1997;227:173-6.

54 Smith WB, Gamble JR, Clark-Lewis I, et al. Interleukin-8 induces neutrophil transendothelial migration. Immunology 1991;72:65-72.

55 Kostulas N, Kivisakk $P$, Huang $Y$, et al. Ischemic stroke is associated with a systemic increase of blood mononuclear cells expressing interleukin-8 mRNA. Stroke 1998;29:462-6

56 Tarkowski E, Rosengren L, Blomstrand C, et al. Intrathecal release of pro- and anti-inflammatory cytokines during stroke. Clin Exp Immunol 1997:110:492-9.

57 Nandate K, Vuylsteke A, Crosbie AE, et al. Cerebrovascular cytokine responses during coronary artery bypass surgery: specific production of interleukin- 8 and its attenuation by hypothermic cardiopulmonary bypass. Anesth Analg 1999:89:823-8.

58 Losy J, Zaremba J. Monocyte chemoattractant protein-1 is increased in the cerebrospinal fluid of patients with ischemic stroke. Stroke 2001;32:2695-6.

59 Biber K, Zuurman MW, Dijkstra IM, et al. Chemokines in the brain: neuroimmunology and beyond. Curr Opin Pharmacol 2002;2:63-8.

60 Kostulas N, Pelidou SH, Kivisakk P, et al. Increased IL-1 beta, IL-8, and IL-17 mRNA expression in blood mononuclear cells observed in a prospective ischemic stroke study. Stroke 1999;30:2174-9.

61 Detmers PA, Lo SK, Olsen-Egbert E, et al. Neutrophil-activating protein 1/ interleukin 8 stimulates the binding activity of the leukocyte adhesion receptor CD11b/CD18 on human neutrophils. J Exp Med 1990;171:1155-62.

62 Whalen MJ, Carlos TM, Kochanek PM, et al. Interleukin-8 is increased in cerebrospinal fluid of children with severe head injury. Crit Care Med 2000;28:929-34

63 Gaetani P, Tartara F, Pignatti $P$, et al. Cisternal CSF levels of cytokines after subarachnoid hemorrhage. Neurol Res 1998;20:337-42.

64 ladecola C, Ross ME. Molecular pathology of cerebral ischemia: delayed gene expression and strategies for neuroprotection. Ann NY Acad Sci 1997:835:203-17.

65 D'Ambrosio AL, Pinsky DJ, Connolly ES. The role of the complement cascade in ischemia/reperfusion injury: implications for neuroprotection. Mol Med $2001 ; 7: 367-82$

66 Hess DC, Bhutwala T, Sheppard JC, et al. ICAM-1 expression on human brain microvascular endothelial cells. Neurosci Lett 1994;168:201-4.

67 Clark WM, Coull BM, Briley DP, et al. Circulating intercellular adhesion molecule-1 levels and neutrophil adhesion in stroke. J Neuroimmunol 1993;44:123-5.

68 Kim JS, Chopp M, Chen H, et al. Adhesive glycoproteins CDI la and CD18 are upregulated in the leukocytes from patients with ischemic stroke and transient ischemic attacks. J Neurol Sci 1995;128:45-50.

69 Frijns CJ, Kappelle U, van Gijn J, et al. Soluble adhesion molecules reflect endothelial cell activation in ischemic stroke and in carotid atherosclerosis. Stroke 1997;28:2214-18.

70 Fiszer U, Korczak-Kowalska G, Palasik W, et al. Increased expression of adhesion molecule CD 18 (LFA-1 beta) on the leukocytes of peripheral blood in patients with acute ischemic stroke. Acta Neurol Scand 1998;97:221-4.

71 Fassbender K, Mossner R, Motsch L, et al. Circulating selectin- and immunoglobulin-type adhesion molecules in acute ischemic stroke. Stroke 1995;26:1361-4.

72 Shyu KG, Chang H, Lin CC. Serum levels of intercellular adhesion molecule-1 and E-selectin in patients with acute ischaemic stroke. I Neurol 1997:244:90-3.

73 Stanimirovic DB, Wong J, Shapiro A, et al. Increase in surface expression of ICAM-1, VCAM-1 and E-selectin in human cerebromicrovascular endothelial cells subjected to ischemia-like insults. Acta Neurochir Suppl 1997;70:12-16.

74 Bitsch A, Klene W, Murtada L, et al. A longitudinal prospective study of soluble adhesion molecules in acute stroke. Stroke 1998:29:2129-35.

75 Kaluza J, Krupinski J, Kumar P, et al. VCAM-1 expression on reactive and tumour astrocytes. Folia Histochem Cytobiol 1994;32:17-20.

76 Gelati M, Corsini E, De Rossi M, et al. Methylprednisolone acts on peripheral blood mononuclear cells and endothelium in inhibiting migration phenomena in patients with multiple sclerosis. Arch Neurol 2002;59:774-80.

77 Oudega M, Vargas CG, Weber AB, et al. Long-term effects of methylprednisolone following transection of adult rat spinal cord. Eur J Neurosci 1999;11:2453-64

78 Slivka AP, Murphy EJ. High-dose methylprednisolone treatment in experimental focal cerebral ischemia. Exp Neurol 2001:167:166-72.

79 Kim JS, Chopp M, Gautam SC. High dose methylprednisolone therapy reduces expression of JE/MCP-1 mRNA and macrophage accumulation in the ischemic rat brain. J Neurol Sci 1995; 128:28-35.

80 Qizilbash N, Lewington SL, Lopez-Arrieta JM. Corticosteroids for acute ischaemic stroke. Cochrane Database Syst Rev 2000.2.

81 Vuorte J, Lindsberg PJ, Kaste M, et al. Anti-ICAM-1 monoclonal antibody R6.5 (Enlimomab) promotes activation of neutrophils in whole blood. $J$ Immunol 1999;162:2353-7.

82 Rudd JH, Warburton EA, Fryer TD, et al. Imaging atherosclerotic plaque inflammation with $\left[{ }^{18} \mathrm{~F}\right]$ - fluorodeoxyglucose positron emission tomography. Circulation 2002; 105:2708-11.

83 Maini RN, Taylor PC. Anti-cytokine therapy for rheumatoid arthritis. Annu Rev Med 2000;51:207-29.

84 Frenette PS. Locking a leukocyte integrin with statins. N Engl J Med 2001;345:1419-21.

85 Group NSPR. Report, 2002. http://www.ninds.nih.gov/about_ninds/ 04_2002 Stroke PRG Report.htm 